\title{
Sonlu Elemanlar Metodu Kullanarak Farklı Yol Üstyapı Tiplerinin Oturmaya Etkisinin İncelenmesi
}

\author{
Elif Çiçek ${ }^{1 *}(\mathbb{D}$
}

${ }^{1}$ Hacettepe Üniversitesi, Mühendislik Fakültesi , İnşaat Mühendisliği, Ankara

Geliş / Received: 03/01/2020, Kabul / Accepted: 23/04/2020

\section{Öz}

$\mathrm{Bu}$ çalışmada, farklı yol tiplerinin oturma davranışı üzerine etkisi sonlu elemanlar yöntemi kullanılarak incelenmiştir. Analizlerde aynı temel ve alt temel tabakaları üstüne inşa edilen farklı yol kaplama cinsleri için analiz modelleri oluşturulmuştur. Maksimum büyüklükleri aynı değerde olan statik ve dinamik yüklerde oluşabilecek oturma değerleri için iki boyutlu hesaplamalar yapılmıştır. Farklı tekerlek aralıkları (15, 30, 60 ve $120 \mathrm{~cm}$ ) için statik ve dinamik yükler altında oluşan asfalt ve beton yol tiplerindeki oturma davranışları incelenmiştir. İlk olarak asfalt yol kaplamasında analizler yürütülmüştür. Daha sonra ise beton yol ve yarısı beton yol olup kaplamanın diğer üst yarısının asfalt kaplama olma durumları için analiz sonuçları karşılaştırılmış ve farklılıklar yorumlanmıştır. Böylece tekerlek aralığı, yükleme tipi ve kaplama cinslerinin kara yolunda meydana getirebileceği oturma davranışları nümerik bir çalışma ile değerlendirilmiştir.

Anahtar Kelimeler: Asfalt yol, beton yol, sonlu elemanlar metodu, oturma.

\section{Investigation of The Effect of Different Pavement Types on the Settlement Using Finite Element Method}

\begin{abstract}
In this study, the effect of different road types on sitting behavior was investigated by using finite element method. Analysis models were created for different types of road pavements built on the same base and subbase layers. Two-dimensional calculations were made for the settlement values that can occur in static and dynamic loads with the same maximum values. Settlement behavior of asphalt and concrete road types under static and dynamic loads for different wheel distances $(15,30,60$ and $120 \mathrm{~cm})$ were investigated. First, analyzes were carried out on asphalt pavement. Then, the results of the analysis were compared and the differences were interpreted for the case of the asphalt pavement of the other half of the pavement. Thus, both the wheel spacing, the type of loading and the type of pavement that can occur in the road behavior of the sitting behavior was evaluated with a numerical study.
\end{abstract}

Keywords: asphalt road, concrete road, finite element metod, settlement.

\section{Giriş}

Son y1llarda asfalt ve beton kaplama cinslerine sahip yolların davranışlarındaki farklılıklar önem kazanmıştır. Bilindiği üzere, kara yollarında genellikle asfalt veya beton olmak üzere farklı kaplamalar kullanılabilmektedir. Uygulayıcıların yol kaplama tipine karar verilirken yol performansı önemlidir ve bazı teknik 
özellikler de belirleyici rol oynamaktadır. Diğer bir deyişle, esnek ve rijit olan bu farklı tür kaplamaların tercih sebepleri değişiklik gösterebilmektedir. Oturmaların oluşması önemli problemler arasındadır ve farklı kaplamalara sahip yollar için bu durum değişlik gösterebilecektir ve araç trafiği için alternatifler sunabilmektedir. Ayrıca, farklı yükleme tiplerinin yola etkisi tam anlamıyla bilinmemektedir. Örneğin, aynı koşullarda asfalt veya beton yol kaplaması yapıldığında yolun statik ve dinamik trafik yüklerine maruz olma durumundaki oturma farkları ile ilgili bilgilere ihtiyaç olduğu açıktır. Bu araştırma makalesinde de bu ihtiyaca yönelik bir çalışma yapılmıştır.

Yollar ile ilgili literatürdeki birçok çalışma laboratuvarda, arazide veya sonlu elemanlar metodu kullanan bir program vasitasiyla yapılmıştır. $\mathrm{Bu}$ araştırma yöntemlerinden birisi olan sonlu elemanlar yöntemi ile çalışan bir programın kullanımı, bir elemanının büyük yükler altında tepkisini tahmin etmek amacıyla yaygın bir şekilde kullanılmaktadır (Mulungye vd., 2007; Howard ve Kimberly, 2009; Ranadive ve Tapase; 2013; Faheem ve Hassan; 2014; Lin vd., 2014; Tarefder vd., 2014; Shafabakhsh vd., 2014; Chun vd., 2015; Kadela, 2016; Imaninasab vd., 2016; Zhang vd., 2017). Örneğin, Imaninasab vd. (2016) asfalt yollar için sonlu elemanlar yöntemi ile araştırmışlardır. Chun vd. (2015) arazi koşullarında yapılan ölçümler ile sonlu elemanlarda yapılan analizler ile yolun servis ömrünü incelemişlerdir. Mulungye vd. (2007) sonlu elemanlar programı kullanarak yumuşak zeminler üzerine yapılan esnek yol modelleri üzerine analizler yapmıştır. Dinamik olarak yüklenen yol modelinde dört farklı yük modeli ile analizler tamamlanmıştır. Sonlu elemanlar sonuçlarının arazi verileri ile karşılaştırması yapılarak sonlu elemanlar ile yol analizlerinin incelenebileceği sonucuna varılmıştır. $\mathrm{Bu}$ nedenle, sonlu elemanlar programı ile statik veya dinamik yük olarak tanımlanan farklı trafik akış durumundaki yük durumları için incelemeler yapılabilmektedir. Böylece kara yolu modellerinde oluşabilecek ilave oturmaların tahmininde önemli katk1lar sağlanabilecektir (Acharya vd., 2016).

Literatür incelendiğinde, araştırmaların çoğu tek tekerlek yükü için yapılmıştır. Yol üzerinde iki yükleme durumu olması halinde, yani iki tekerlek yükü olma durumu için yapılan çalışmaların sınırlı sayıda olduğu belirlenmiştir (Al-Hadidy ve Yi-qiu, 2009a, 2009b, 2009c, Bandeira vd., 2009; Mokhtari ve Nejad; 2012; Liu vd., 2017). Fakat yapılan çalışmalar hem sınırlı sayıda hem de genellikle sabit tekerlekler arası mesafe kullanılarak yürütülmüştür. $\mathrm{Bu}$ nedenle tekerlekler arasındaki mesafenin değiştirilerek tekerlek yüklerinin yolda oluşturabileceği oturma değerlerine etkilerinin incelenmesi önemlidir. Ayrıca, araç tipi ve yükleme modellerine göre tekerlekler arası mesafe değişebilmekte ve yolda farklı oturmalar gözlemlenebilmektedir. Tekerlekler arasının yakın veya uzak olması durumları için sonuçların karşılaştırılmasının farklı yol ve yükleme tiplerinde incelenmesine gerek duyulmaktadır.

Bilindiği üzere karayolu üst yapıları genel olarak asfalt ve beton yol olmak üzere iki şekilde modellenmektedir. Dünyadaki yollar için çoğunlukla asfalt yol kaplaması kullanılmaktadır ve araştırmaların büyük bir çoğunluğu bu yol tipleri için yapılmıştır. Fakat bakım giderleri ve servis ömrü açısından daha avantajlı olan beton yollar iyi bir alternatif olabilmektedir. Beton yolda kullanılacak malzemenin dayanıklı olmasının yanı sıra bulunduğu ortamdan da etkilenmemesi ve artan taşıt trafiğinin yol üst 
yapisında önemli problemlere neden olmaması gerekmektedir. Otoyolların yapımında beton malzemesi kullanıldığında yapının uzun süreli performans sağlayabilmesi için özen gösterilmesi gereken bazı hususlar bulunmaktadır. Ulaştırma mühendisliğinde kullanılan betonarme yapılarda kaza riskini arttırmada rol oynayabilen çatlakların oluşmasının önüne geçilmesi büyük önem taşımaktadır. Böylece, son y1llarda beton yollar ile ilgili de araştırmalar hız kazanmış durumdadır. Örneğin, Rooholamini vd. (2018) silindirle sıkıştırılmış beton yol kaplamaların mekanik özellikleri üzerindeki etkisini değerlendirmeye çalışmıştır. Laboratuvar deneyleri yaparak sonuçları incelemişlerdir. Bing vd. (2014) sonlu elemanlar yöntemi ile beton yol modeli için derzler ile ilgili analizler yapmışlardır. Fakat asfalt ile beton yollarda oluşabilecek tekerlek izi yani yükten etkilenen oturma davranışının karşılaştırılmasına ihtiyaç duyulmaktadır. $\mathrm{Bu}$ nedenle, bu çalışmada, aynı temel ve alt temel tabakaları üstüne yapılan farklı yol kaplama cinsleri için modeller oluşturulmuştur.

$\mathrm{Bu}$ çalışmada, literatürde görülen eksik noktalar tespit edilerek farklı yol kaplamaları için sonlu elemanlar analizleri yapılmıştır. Maksimum büyüklükleri aynı değerdeki statik ve dinamik yük durumları için ayrı ayrı oluşabilecek oturma değerleri incelenmiştir. Tekerlekler arası mesafe değiştirilerek yükleme sonrası oluşan ilave oturmalar beton ve asfalt yol tipleri için karşılaştırılmıştır. Farklı yükleme koşulları için yol yüzeyinde yatay eksende oluşan oturmalar ve tekerleğin ortasında, tekerlek kenarı ve tekerlekler arasındaki noktalarda yolda görülen oturmaların yol tabaka kalınlığı boyunca değişimleri incelenmiştir. Ayrıca, bilindiği üzere altta beton üstünün ise asfalt olması ile ilgili pek çalışma bulunmamakta ve merak konusu olmaktadır. $\mathrm{Bu}$ nedenle bu çalışmadaki analizler ile farklı yol modellerinin üstünlüğü karşılaştırılmıştır.

\section{Materyal ve Metot}

Bu çalışmada, sonlu elemanlar programı olan Plaxis 2018 kullanılarak farklı yol kaplaması için analizler yapılmıştır. İki teker arasındaki mesafe değerleri değiştirilerek tekerlek yüklerinin yolda oluşturabileceğgi oturma değerlerine etkileri incelenmiştir. Ayrıca, tekerlekler arası mesafe değişimi (z) farklı kaplama çeşitlerine sahip yol modelleri için incelenmiştir. Asfalt, beton ve altta beton üstte asfalt kaplama olarak modellenen değişik kaplamalı yol modelleri dikkate alınmıştır. Her bir kaplama modelinde değişik tekerler arası mesafe değişimleri $(\mathrm{z}=15,30,60$ ve $120 \mathrm{~cm})$ için yeni analiz modelleri oluşturulmuştur. Analizlerde kullanılan model ve malzemeler, literatürden seçilmiştir (Helwany vd., 1998; Chandra vd., 2008; Khavassefat vd., 2015; Djellali vd., 2017). Modellin sınır koşullarında alttaki eksen oturmalara sınırlanmış, yolun yanları ise düşey doğrultuda sınırlanmıştır (Ling vd., 2001; Ling vd., 2003). Analiz modellerinin sınır koşullarından etkilenmemesi için yol genişliği $10 \mathrm{~m}$ olarak alınmıştır. S1kı mesh olarak alınan, mesh elemanları her modelde aynı alınmış sadece malzeme ve tekerlek parametreleri değişmiştir. Yol dolgu zemini olarak alt temel tabakada üniform özelliklere sahip $21 \mathrm{kN} / \mathrm{m}^{3}$ birim hacim ağırlıklı dolgu malzemesi kullanılmıştır. Sürtünme açısı $45^{\circ}$, Young modülü $5000 \mathrm{kPa}$ ve poisson oranı 0.35 'dir. Üst tabakadaki temel tabakası zemininin ise Young modülü $10000 \mathrm{MPa}$ alınmıştır. Zemin tabakaları Mohr-Coulomb malzeme modeli ile modellenmiştir. Zemin parametreleri literatürden seçilmiştir (Ling vd., 2001; Ling vd., 2003). Alt temel tabaka kalınlığ $90 \mathrm{~cm}$, üst tabaka $30 \mathrm{~cm}$ ve kaplama 
kalınlığı ise $15 \mathrm{~cm}$ alınmıştır. Kaplama olarak ise ilk olarak asfalt malzeme, sonrasinda beton yol ve en son olarak da kaplamanın alt kısmı beton diğer yarısı da asfalt olması halinde modeller oluşturulmuştur (Şekil 1). Kullanilan kaplama malzemelerinin özellikleri Çizelge 1'deki gibi özetlenmiştir.. Literatürde belirtildiği gibi elastik sınırlandırmalar içinde modellenmişlerdir (Helwany vd., 1998; Djellali vd., 2017). Analizlerde tekerlek izine göre ortalama bir değer için çevrim işlemleri yapıldığında genellikle $15 \mathrm{~cm}$ yarıçaplı bir tekerlek izi için yaklaşık olarak $550 \mathrm{kPa}$ değerinde basınç yükü temsil edilebilmektedir (Helwany vd., 1998; Abu-Farsakh vd., 2014; Abu-Farsakh vd., 2016). Bu nedenle tekerlek genişliği yani yükleme genişliği sabit alınmıştır. Yollardaki davranış statik veya dinamik yükleme durumlarına göre incelenebilmektedir. Fakat iki farklı yükleme durumu için oluşacak değişimler tam anlamıyla bilinmemektedir. Bu nedenle bu çalışmada statik yükleme için $550 \mathrm{kPa}$, dinamik yükleme modeli için ise $0.025 \mathrm{sn}$ aralığ1 için Şekil 2'deki yük-zaman modeli verilen yük uygulanmıştır. Farklı yükleme koşulları için yol yüzeyinde yatay eksende oluşan oturmalar ve tekerleğin ortasında, tekerlek kenarı ve tekerlekler arasındaki noktalarda yolda görülen oturmaların yol tabaka kalınlığı boyunca değişimleri incelenmiştir. Bunlar, teker ortası yüklemenin yapıldığı merkez nokta, tekerlek yükünün tanımlandığı yükleme çizgilerinin hemen dişı ve yolun merkezi diğer bir deyişle iki tekerin ortasındaki değişkenlerdir. Böylece farklı nokta, model ve özelliklerde araştırma yapılmıştır.

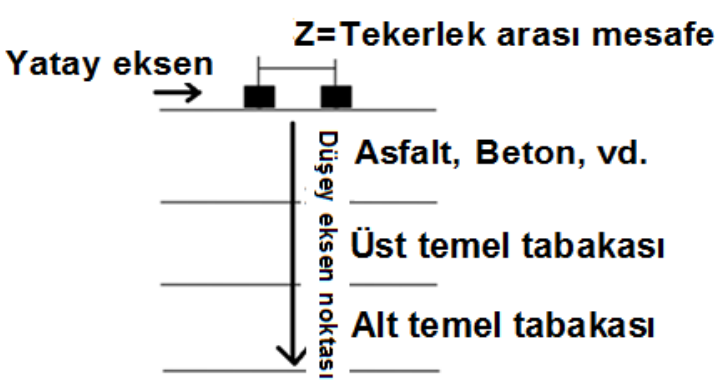

Şekil 1. Yol modeli

Tablo 1. Kaplama malzeme özellikleri

\begin{tabular}{|c|c|c|c|c|}
\hline $\begin{array}{l}\text { Tabaka } \\
\text { tipi }\end{array}$ & $\begin{array}{l}\text { Elastisite } \\
\text { Modülü } \\
(\mathrm{MPa})\end{array}$ & $\begin{array}{l}\text { Poisson } \\
\text { oranı }\end{array}$ & $\begin{array}{l}\text { Birim } \\
\text { hacim } \\
\text { ağırlığ } 1 \\
\left(\mathrm{kN} / \mathrm{m}^{3}\right)\end{array}$ & Referans \\
\hline Beton & 28000 & 0.18 & 24 & $\begin{array}{l}\text { (Helwany } \\
\text { vd., 1998; } \\
\text { Kim vd., } \\
2016)\end{array}$ \\
\hline Asfalt & 5400 & 0.35 & 25 & $\begin{array}{l}\text { (Djellali } \\
\text { vd., 2017) }\end{array}$ \\
\hline
\end{tabular}

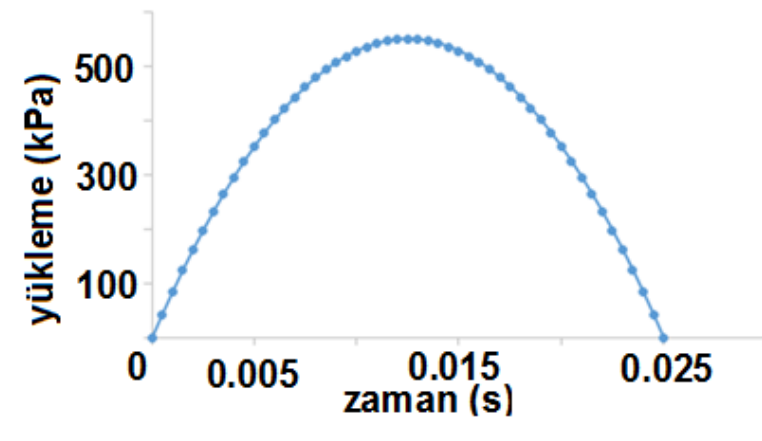

Şekil 2. Dinamik yük

\section{Bulgular ve Tartışma}

Sonlu elemanlarda yapilan analizlerde karayolu örneklerinin her biri için hem statik hem de dinamik olarak etkiyen $550 \mathrm{kPa}$ değerindeki yüklemeler ile ayrı ayrı hesaplamalar yapılmıştır. Her bir işlem asfalt, beton ve yarısı beton üst bölümü asfalt olan kaplama modellerine sahip farklı yol modelleri için ayrı ayrı tekrar edilmiştir. Farklı yükleme koşulları için yol yüzeyinde yatay eksende oluşan oturmalar ve tekerleğin 
ortasında, tekerlek kenarı ve tekerlekler arasındaki noktalarda yolda görülen oturmaların yol tabaka kalınlığı boyunca değişimleri incelenmiştir. Aşağıda hesaplamalarda bulunan sonuçlar ve karşılaştırmaları verilmişstir.

\subsection{Statik Trafik Yükü}

\subsubsection{Asfalt kaplamalı yol durumu}

Yol kaplaması asfalt olan modeller dikkate alındığında kaplama tabakası sabit kaplama kalınlığı için yapılan işlemlerde; yol genişliği boyunca yol yüzeyinde meydana gelen oturma davranışının değiştiği gözlemlenmiştir (Şekil 3). Tekerler arası mesafe arttıkça merkez bölgede meydana gelen oturma miktarının ise azalan bir davranış sergilediği belirlenmiştir. Sonuçlarda, yatay eksen yol yüzeyini, düşey eksen noktası ise yolun tabaka derinliklerine doğru olan mesafeleri temsil etmektedir (Şekil 1).

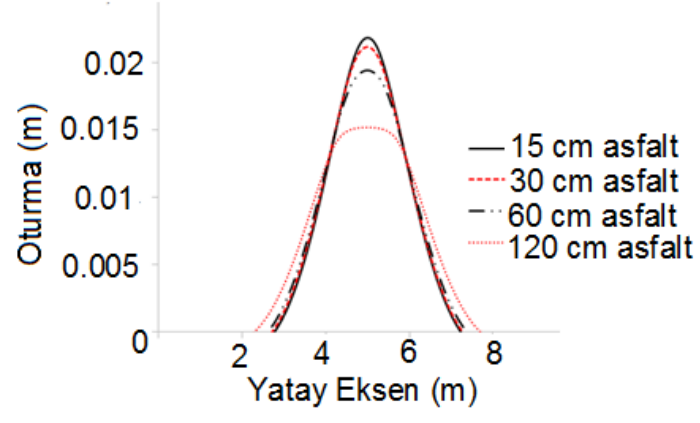

Şekil 3. Farklı tekerlek aralıkları için yüzeydeki oturma davranışı

Daha ağır taşıt yükü için yük miktarının arttırılması durumunda yolun yükü taşıyamadığı ve yolda büyük oturmaların oluşmaya başlayabileceği gözlenmiştir. Gerçek yol modellerinde de olduğu gibi taşıt trafiğine ve servis hizmetine yolun kapatılması gerekebilmektedir. Yolda araç yükünün farklı bölgeleri için analiz sonuçları da incelenmiştir. Örneğin; tekerleğin ortasında, tekerlek kenarı ve tekerlekler arasındaki yolda görülen oturmaların yol tabaka kalınlığ 4'deki gibi hesaplanmıştır. Tekerlekler arası mesafe $\mathrm{z}=15 \mathrm{~cm}$ olduğunda tekerlekler arasındaki merkez noktada $(5 \mathrm{~m})$ her iki tekerlek yükünün de etkisinin olduğu ve daha büyük bir oturma miktarı oluşabildiği belirlenmiştir. Beklendiği üzere, tekerleklerin dışındaki kenarda ise diğer bölgelere nispeten daha az oturma meydana gelmiştir.

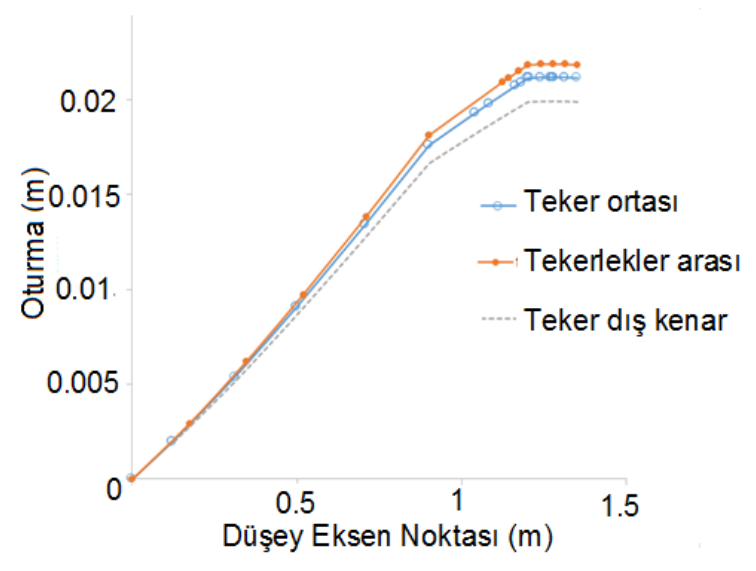

Şekil 4. Farklı tekerlek aralıkları için asfalt kaplamalı modellerde düşey eksen boyunca oturma

Asfalt yol kaplamasında statik yüklemede farklı tekerlek aralıkları için $(\mathrm{z}=15 \mathrm{~cm}, 30 \mathrm{~cm}$, $60 \mathrm{~cm}$ ve $120 \mathrm{~cm}$ ) yapilan analizlerde görülmüştür ki tekerler arası mesafe arttıkça yolda oluşabilecek oturma değerleri tabakaların düşey yönünde de azalmaktadır (Şekil 5). Mesafe kısaldığında ise iki teker yükü birlikte davranıyormuş gibi bir etki göstermeye başlamışlardır. Tüm analiz şartlarında farklı tekerlek aralıkları dahi alınsa $(\mathrm{z}=15 \mathrm{~cm}, 30 \mathrm{~cm}, 60 \mathrm{~cm}$ ve $120 \mathrm{~cm}$ için) tekerlekler arasında nispeten daha fazla oturma oluşmakta, fakat tekerlek dış kenarında ise en az oturma etkisi görülebilmiştir. 


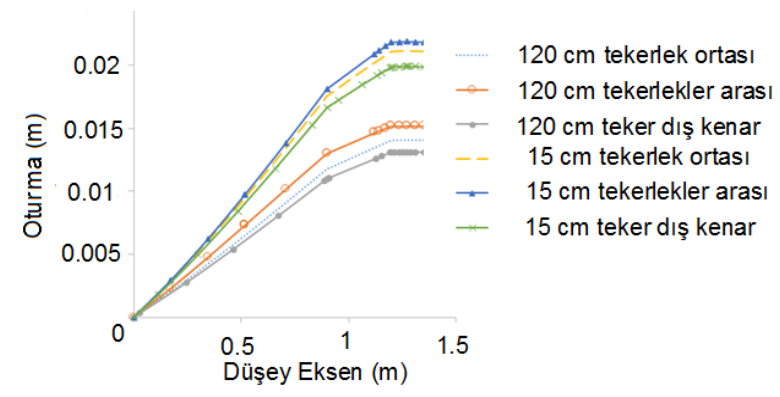

Şekil 5. Asfalt kaplamalı modeller için farklı noktalardaki oturmalar

\subsubsection{Beton kaplamalı yol durumu}

Bilindiği üzere son yıllarda gündemde olan ve asfalt yol kaplamalarına alternatif olarak gösterilen beton yol modeli ülkemiz için de önemlidir. $\mathrm{Bu}$ nedenle benzer işlemler kaplamanın beton gibi daha da güçlü bir malzeme kullanılması durumunda da tekrar edilmiştir. Tekerlekler arası mesafenin 15, 30, 60 ve $120 \mathrm{~cm}$ olması durumları için analizler yinelenmiştir. $\mathrm{Bu}$ modellerde de asfalt kaplamada olduğu gibi tekerlekler arası mesafenin küçük olması halinde daha fazla oturma görülmüştür (Şekil 6 ve Şekil 7). Maksimum oturmanın ise $\mathrm{z}=15 \mathrm{~cm}$ olan tekerleklerin arasında yani tekerleklerin en yakın olduğu durumda oluştuğu gözlenmiştir.

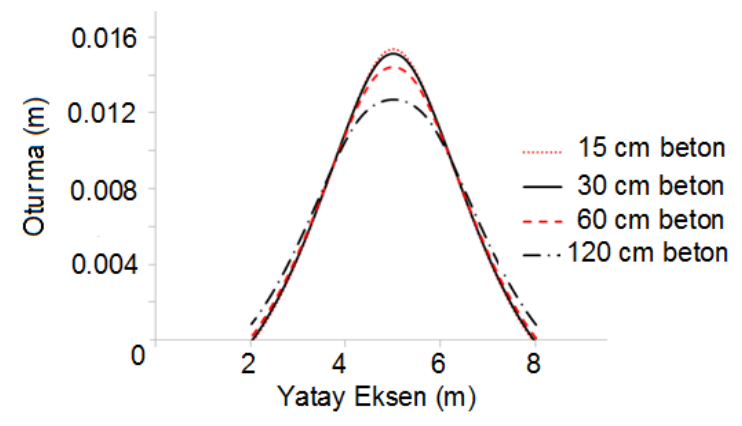

Şekil 6. Beton kaplamalı modeller için yüzey oturma davranış1

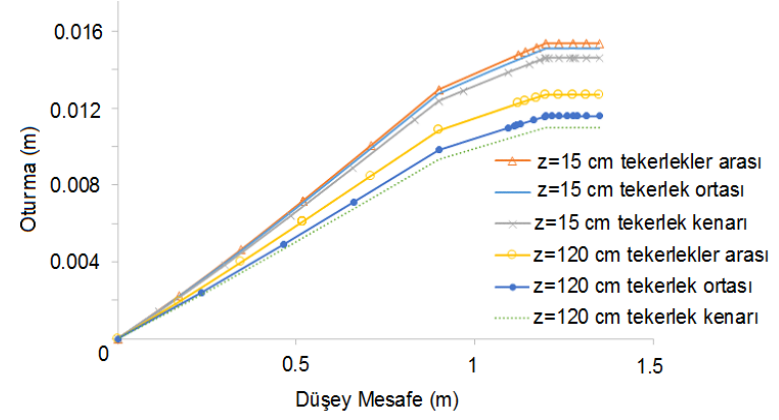

Şekil 7. Beton kaplamalı modeller için farklı noktalardaki oturmalar

Asfalt ile beton yol kaplama modellerinin arasındaki farkın daha iyi incelenebilmesi amacıyla Şekil 8'de yatay eksen yani yol yüzeyindeki oturma değişiminin incelenmesini verilmektedir. Görüldüğü üzere beklendiği gibi asfalt kaplamalı yollarda daha fazla oturma gözlenmiştir. $15 \mathrm{~cm}$ aralık için beton kaplamalı model $\mathrm{z}=120 \mathrm{~cm}$ aralık için asfalt kaplamalı model ile tekerlekler arasındaki noktada neredeyse benzer oturma değeri vermesine rağmen yan kısımlardaki oturmalar da farklılık göstermiştir. Örneğin $120 \mathrm{~cm}$ aralıklarda daha geniş bir alanda daha büyük oturmalar görülebilmiştir.

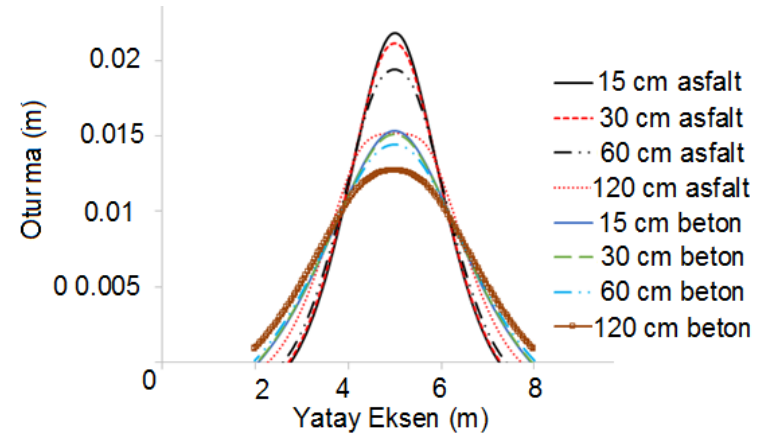

Şekil 8. Yüzeydeki oturmanın asfalt ve beton yol için karşılaştırması

\subsubsection{Yarısı beton üstünde asfalt kaplama olması durumu}

Bilindiği üzere asfalt ve beton yolların birbirleri üzerinde çeşitli üstünlükleri olabilmektedir. Yolun alt kısmının beton olup daha uzun ömürlü olması üstünün ise araç 
seyahati konforu açısından asfalt olması durumu da bu çalışmada incelenmeye çalışılmıştır. Diğer analizlerde olduğu gibi farklı tekerlek aralıkları için tekerlek yüklemesi yapılmış ve gözlemlenen oturma davranışları değerlendirilmeye çalışılmıştır. Şekil 9'da yol yüzeyinde meydana gelen oturma miktarları ve Şekil 10'da ise yol düşeyinde farklı tekerlek konumuna göre oturma miktarları değişik tekerlek genişlikleri için hesaplanmıştır. $\mathrm{Bu}$ modellerde de tekerlek aralığının azlığı daha etkili olmuştur.

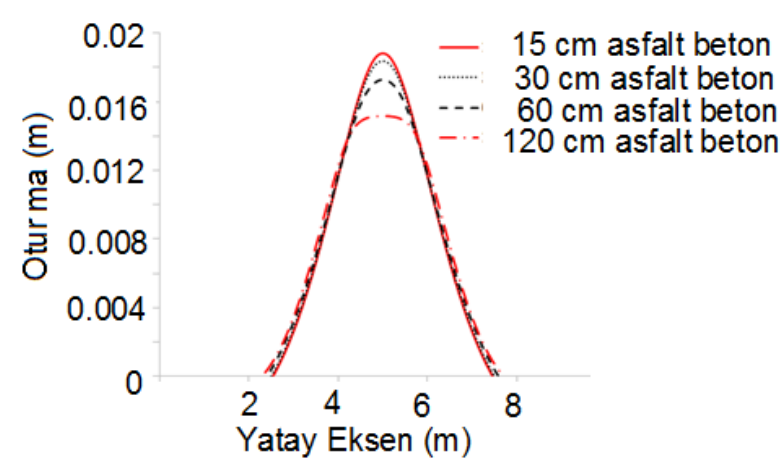

Şekil 9. Yarısı asfalt yarısı beton yol olan modellerde yüzeydeki oturma davranışı

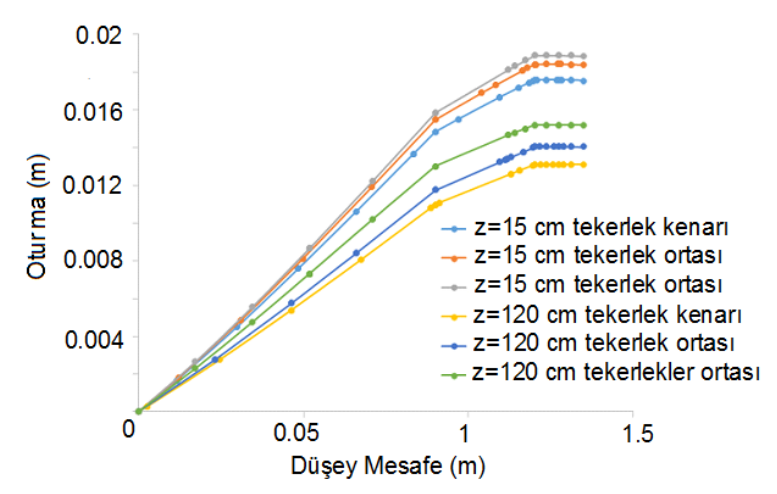

Şekil 10. Yarısı asfalt yarısı beton kaplamalı modeller için oturmalar

Farklı yol kaplamalarının davranışı en fazla oturma yapan tekerlek aralığ $1 \mathrm{z}=15 \mathrm{~cm}$ için karşılaştırıldığında (Şekil 11) beton yol asfalta nazaran yaklaşık 1.4 kat daha az oturma yapmıştır. Yolun yarısı asfalt yarısı beton olması durumunda ise 1.16 kat daha az oturma meydana gelmiştir. Görüldüğü üzere maksimum oturma küçük tekerlek aralığında tekerlekler arasindaki merkez noktada (5m'de) meydana gelmiştir. Yol kaplamasının üst yarısında beton ve üstünde asfalt kullanılması halinde beton kaplı yola nazaran daha dar alana yük yayılırken oturma miktarı da yolun merkez noktasında uzaklaştıkça beton yoldan daha azdir. Fakat yolun merkezinde yani iki tekerlek arasında en az oturma beton yolda en fazla ise asfalt yolda meydana gelmiştir.

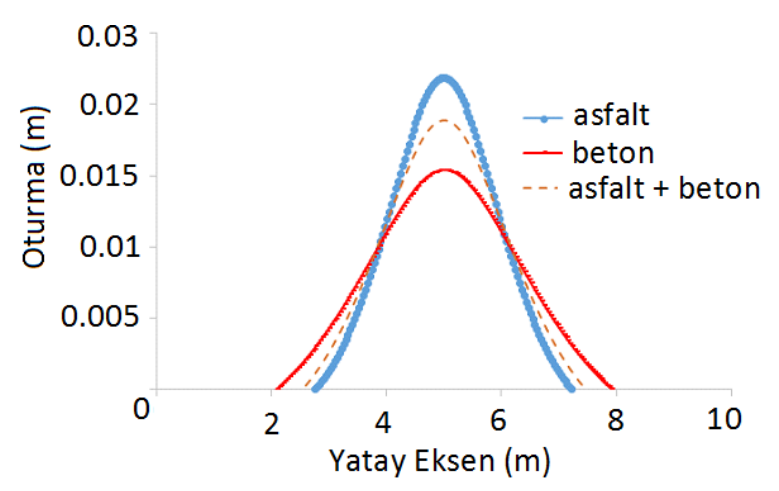

Şekil 11. Farklı yol tiplerinin karşılaştırması

\subsection{Dinamik Trafik Yükü}

$\mathrm{Bu}$ analiz grubunda ise Şekil 2'deki maksimum değeri $550 \mathrm{kPa}$ olan dinamik tekerlek yükü 0.025 sn için tek bir yük teması gerçekleşmiş gibi düşünülerek etki ettirilmiştir. Hesaplamalar ve modeller asfalt, beton ve yarısı beton olup kaplama üstünde asfalt serilen yol modelleri için ayrı ayrı yapılmış ve yol yüzeyinde oluşabilecek maksimum oturma değerleri incelenmiştir (Şekil 12). Bu analizlerde de maksimum oturma davranış1 $\mathrm{z}=15 \mathrm{~cm}$ tekerlek açıklığında gözlenmiştir. $z=120$ olduğunda ise diğerlerine nazaran daha az oturma olmuştur. Dinamik yüklemede asfalt ve beton arasında statiğe nazaran daha farklı bir davranış izlenmiştir. 


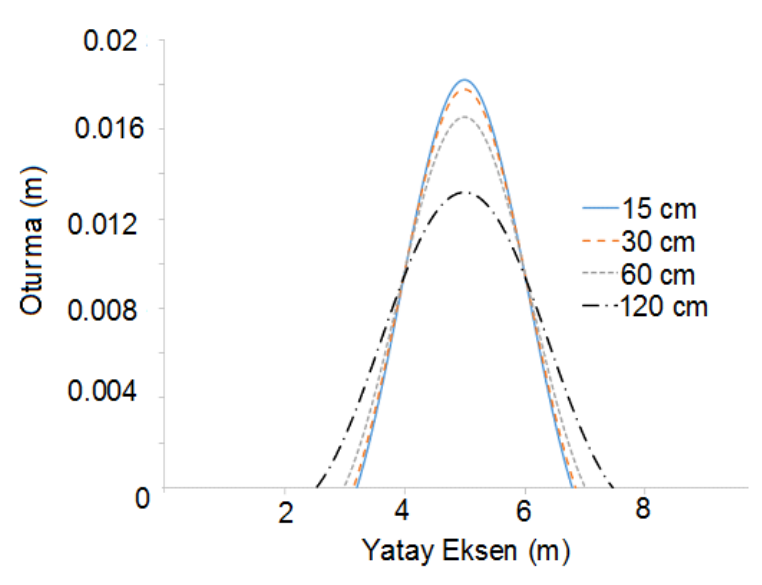

a

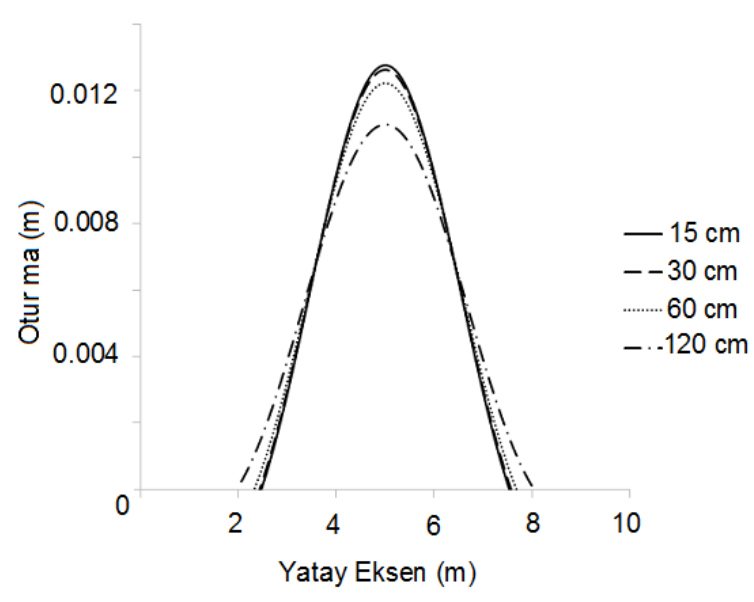

b

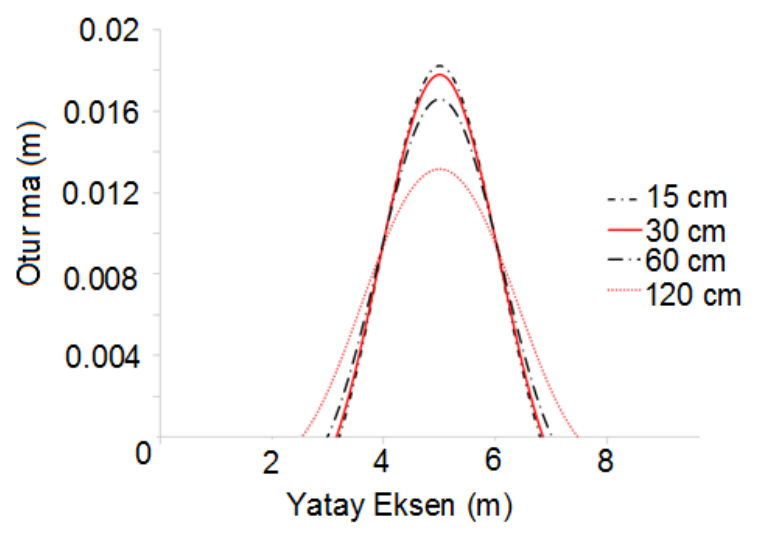

c

Şekil 12. Farklı yol tipleri için dinamik trafik yükü altında yol yüzeyindeki oturmalar; a. Asfalt yol modeli, b. Beton yol modeli, c. Yarısı beton yarısı asfalt yol modeli
Yolun aynı maksimum yükle statik veya dinamik olarak yüklenme durumlarının karşılaştırılması Şekil 13'teki gibi detaylı verilmiştir. Şekil 14'te ise oturmaların rakamsal olarak değerlendirilmesi verilmiştir. Asfalt için yol yüzeyinde $0.02 \mathrm{~m}$ değerine kadar oturma olurken beton yolda bu değer $0.013 \mathrm{~m}$ değerine kadar düşmektedir. Yol yüzeyinde daha fazla oturma olurken altlarda azalmıştır. $z=120 \mathrm{~cm}$ tekerlek açıklığ dinamik yüklemede oturma daha az olurken $\mathrm{z}=15 \mathrm{~cm}$ tekerlek açıklığında statik yüklemede en fazla oturma görülmektedir. Ayrıca farklı kaplama özelliklerine göre statik ile dinamik yükleme arasındaki farklar da değişmektedir. Asfalt kaplama için yine tekerlekler arasının yakın olması durumunda daha fazla oturma miktarı oluşmuştur. Fakat statik oturma miktarı dinamiğe nazaran $\mathrm{z}=15 \mathrm{~cm}$ tekerlek arası için ortalama $0.5 \mathrm{~cm}$, $\mathrm{z}=120 \mathrm{~cm}$ tekerlek aralığ 1 için ise $0.25 \mathrm{~cm}$ kadar farklı oturma oranı çıkmıştır. Ayrıca $\mathrm{z}=120 \mathrm{~cm}$ statik yüklemede daha geniş olana daha fazla oturma davranışı sergilemiştir. Beton yol için yapılan analizde ise hem $\mathrm{z}=15 \mathrm{~cm}$ hem de $\mathrm{z}=120 \mathrm{~cm}$ tekerlek aralıkları için dinamik ile statik yüklemeler arasında benzer oturma farkı oluşmuştur (yaklaşık $0.2 \mathrm{~cm}$ ). Fakat asfalt kaplamaya nazaran 120 $\mathrm{cm}$ statik analizde daha az yol genişliği oturma davranışından etkilenmiştir. Ayrıca beton yol oturma farkının da azalmasına neden olmuştur. Yolun kaplama kalınlığının yarısına beton üstüne de asfalt serilmesi durumunda ise $\mathrm{z}=15 \mathrm{~cm}$ için $0.1 \mathrm{~cm}, \mathrm{z}=120 \mathrm{~cm}$ için ise yaklaşık $0.2 \mathrm{~cm}$ oturma farklı oluşmuştur. Kaplama malzeme çeşidi değiştikçe hem statik hem de dinamik davranışta farklılıklar oluşmuştur. Fakat tüm üç şekilde de değişmeyen en fazla oturmanın $\mathrm{z}=15 \mathrm{~cm}$ modeli için statik yükleme durumları, en az oturmay ise $z=120 \mathrm{~cm}$ tekerlek aralığında dinamik yükleme şartının sağladığı belirlenmiştir. Beton yol kaplamasında en az, 
asfaltta ise daha fazla oturma oluşmaktadır. Yarı yarıya kullanılma durumunda ise asfalta nazaran daha az oturma değerleri ile avantaj sağlamıştır. Ayrıca, bilindiği üzere beton yollarda oturma daha yüzeysel olurken asfalt kaplamalı yollarda daha derinlemesine meydana gelebilmektedir. Statik ve dinamik yüklemelerin karşılaştırılmasında ise statik yüklerin dinamik yükleme durumu sonucuna nazaran daha yüzeysel maksimum oturma şekilleri çıkardı̆̆ 1 belirlenmiştir. Örneğin Şekil 14'de $15 \mathrm{~cm}$ tekerlekler arası mesafe için farklı yükleme koşullarındaki karşılaştırmayı vermektedir. $\mathrm{Bu}$ şekil incelendiğinde oturma şekillerinin değiştiği net olarak görülebilmektedir.

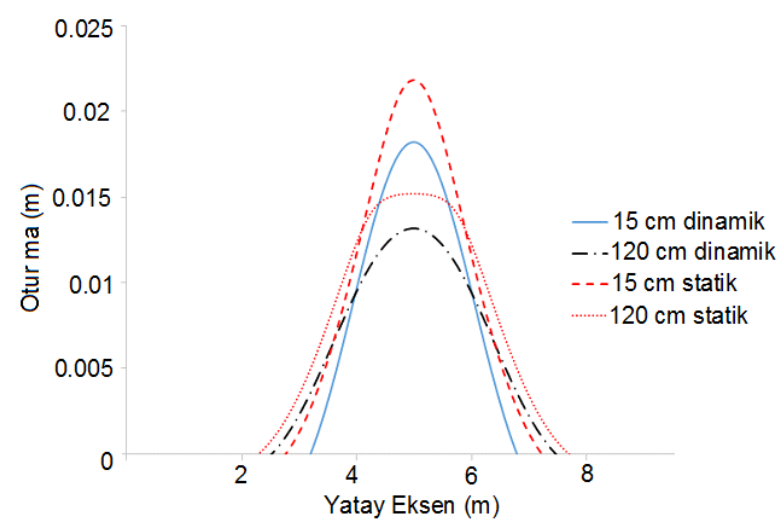

a

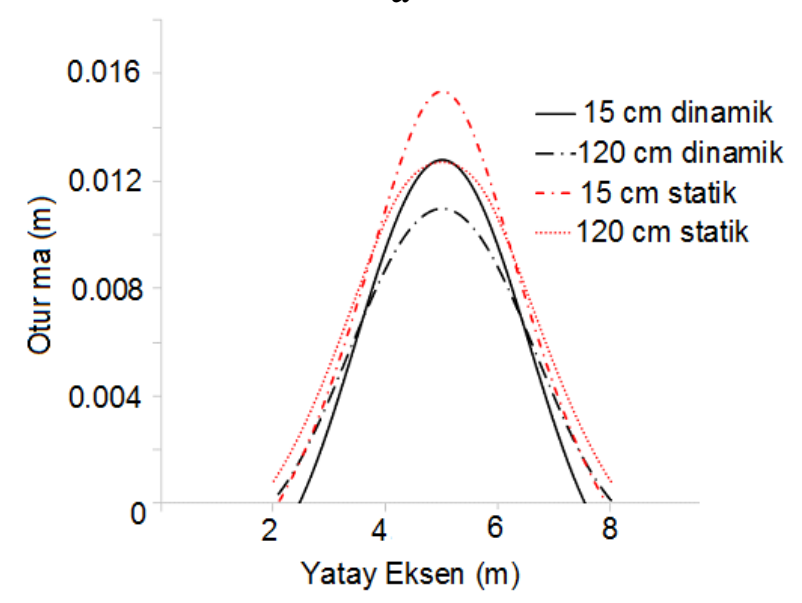

b

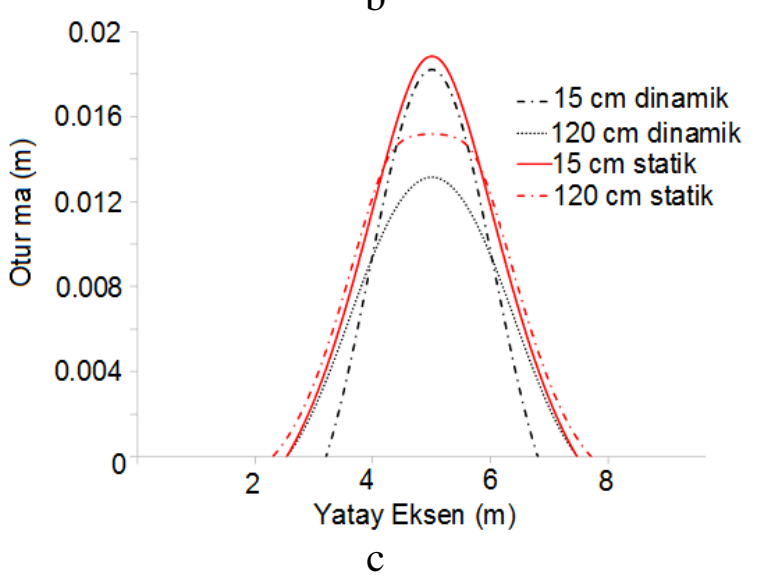

Şekil 13. Statik ve dinamik yükleme karşılaştırması; a. Asfalt yol modeli, b. Beton yol modeli, c. Yarıs1 beton yarıs1 asfalt yol modeli

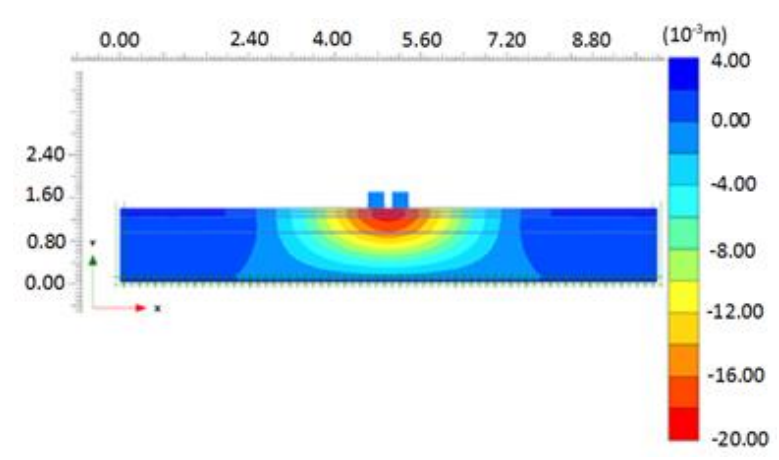

$\mathrm{a}$

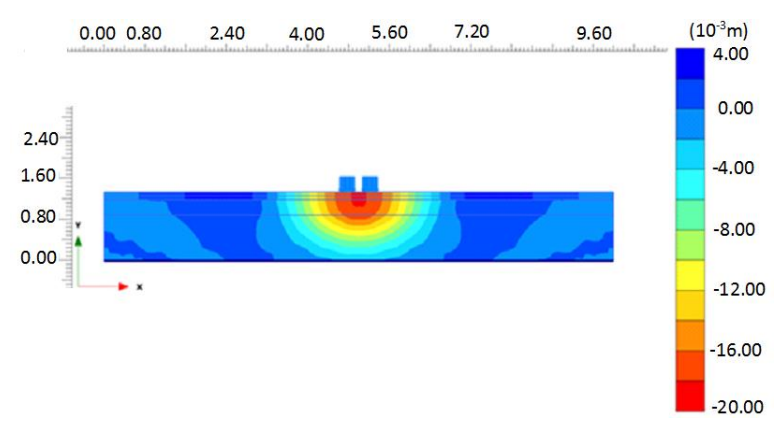

b 


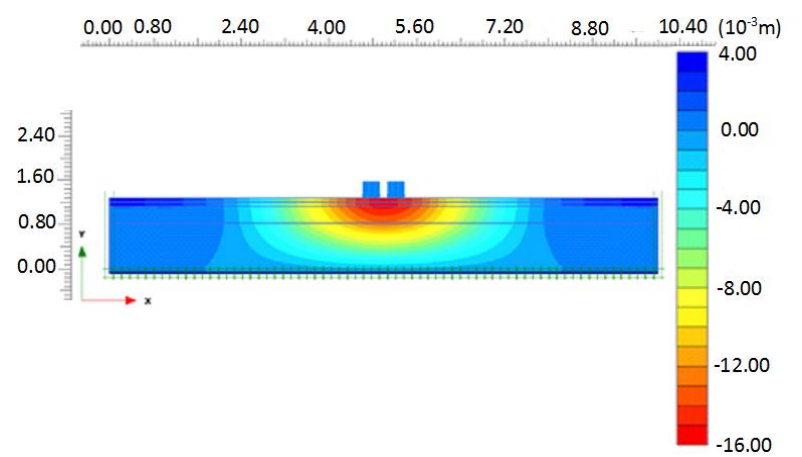

c

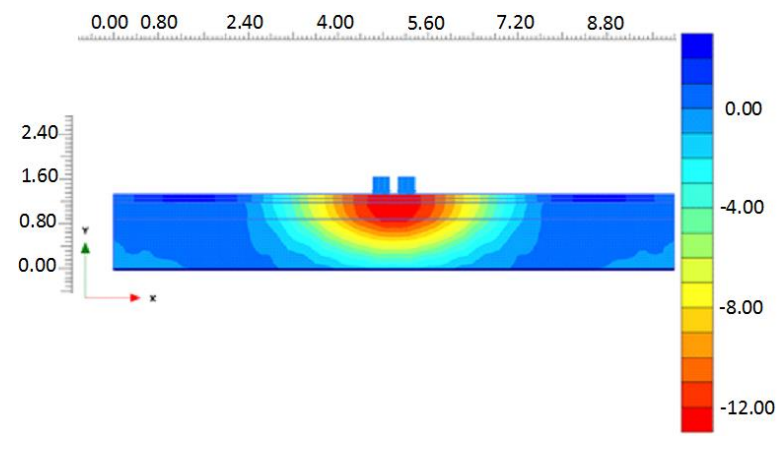

d

Şekil 14. Statik ve dinamik yol modellerinin karşılaştırılması; a. Asfalt yolda statik yükleme; b. Asfalt yolda dinamik yükleme, c. Beton yolda statik yükleme, d. Beton yolda dinamik yükleme.

Sonuçlar literatürdeki çalışmalarla karşılaştırıldığında asfalt yani esnek kaplamalı yollarda oturma davranışı esnek yol için uygun sonuçlar vermiştir (Imaninasab vd., 2016; Chun vd., 2015; Mulungye vd., 2007). Fakat daha öncede belirtildiği üzere literatürde statik ve dinamik yükleme şekillerinin asfalt ve beton yollar için karşılaştırması ile ilgili pek çalışma yoktur. $\mathrm{Bu}$ durum da bu çalışmanın özgünlüğü ve önemini göstermektedir. Böylece, hem literatüre hem de uygulama için önemli bir bilgi sağlandığı düşünülmektedir.

\section{Sonuç ve Öneriler}

Bu çalışmada statik ve dinamik yükler altında farklı yol kaplama cinslerinin oturma davranışları incelenmiştir. İki tekerlek arasındaki yatay mesafeler değiştirilerek oturmaya etkileri karşılaştırılmıştır. Elde edilen sonuçlar aşağıdaki gibi özetlenmiştir;

Tekerler arası mesafe arttıkça merkez bölgede (5m) oturma miktarının azalan bir davranış sergilemektedir. Tekerlekler arası mesafe $\mathrm{z}=15 \mathrm{~cm}$ olduğunda tekerlekler arasındaki merkez noktada her iki tekerlek yükünün de etkisinin olduğu ve daha büyük bir oturma miktarı oluşabildiği belirlenmiştir. Tüm kaplama modellerinde genellikle maksimum oturmanın $\mathrm{z}=15 \mathrm{~cm}$ olan tekerleklerin arasında oluştuğu gözlenmiştir. Tekerleklerin dışındaki kenarlarda ise diğer bölgelere nispeten daha az oturma meydana gelmiştir. Genellikle, asfalt kaplamalı yollarda beton yol modellerine nazaran daha fazla oturma miktarı gözlenmiştir. $z=15 \mathrm{~cm}$ aralık için beton kaplamalı model $\mathrm{z}=120 \mathrm{~cm}$ aralık için asfalt kaplamalı model ile tekerlekler arasındaki noktada neredeyse benzer oturma değeri vermesine rağmen yan kısımlardaki oturmalar da farklılık göstermiştir. Yol kaplamasının üst yarısında beton ve üstünde asfalt kullanılması halinde beton kaplı yola nazaran daha dar alana yük yayılırken oturma miktarı da yolun merkez noktasında uzaklaştıkça beton yoldan daha azdır. Fakat yolun merkezinde yani iki tekerlek arasında en az oturma beton yolda en fazla ise asfalt yolda meydana gelmiştir. Dinamik yükleme durumunda ise maksimum oturma davranışı yine $\mathrm{z}=15 \mathrm{~cm}$ tekerlek açıklığında yani tekerleklerin birbirine daha yakın olma durumlarında gözlenmiştir. Ayrica hem asfalt hem de beton yol modelleri için statik yükleme durumuna nazaran daha az oturma değerleri elde edilmiştir, fakat tüm yol yüzeyinde oluşan oturma dağılımı statik duruma nazaran daha farklı olmuştur. Ayrıca, bilindiği üzere beton yollarda oturma daha yüzeysel olurken asfalt kaplamalı yollarda daha derinlemesine meydana gelebilmektedir. 
Statik ve dinamik yüklemelerin karşılaştırılmasında ise statik yüklerin dinamik yükleme durumu sonucuna nazaran daha yüzeysel maksimum oturma şekilleri çıkardığı belirlenmiştir.

\section{Teşekkür}

$\mathrm{Bu}$ çalşsmanın yürütülmesinde kullanılan sonlu elemanlar programının temini için Hacettepe Üniversitesi Bilimsel Araştırmalar Programına (FHD-2017-13555) teşekkür edilmektedir.

\section{Kaynaklar}

Abu-Farsakh, M., Gub, J., Voyiadjis, G.Z. and Chen, Q. (2014). Mechanistic-empirical analysis of the results of finite element analysis on flexible pavement with geogrid base reinforcement, International Journal of Pavement Engineering, 15, 9: 786-798.

Abu-Farsakh, M., Hanandeh, S., Mohammad, L., Chen, Q. (2016). Performance of geosynthetic reinforced/stabilized paved roads built over soft soil under cyclic plate loads. Geotextiles and Geomembranes, 44, 845-853.

Acharya, R., Han, J., Brennan, J.J., Parsons, R.L., and Khatri, D.K. (2016). "Structural response of a low-fill box culvert under static and traffic loading", Journal of Performance of Constructed Facilities, 30 (1): 04014184.

Al-Hadidy, A.I., Yi-qiu, T. (2009a). "Mechanistic analysis of ST and SBSmodified flexible pavements", Construction and Building Materials, 23: 2941-2950.

Al-Hadidy, A.I., Yi-qiu, T. (2009b). "Mechanistic approach for polypropylenemodified flexible pavements", Materials and Design, 30, 1133-1140.

Al-Hadidy, A.I., Yi-qiu, T. (2009c). “Effect of polyethylene on life of flexible pavements", Construction and Building Materials, 23: 1456-1464.

Bandeira, A.A., Fortes, R.M., Merighi, J.V. (2009). "A study of the Hot-Mix Asphalt layer thickness reduction when applied over lateritic soils cement base in airfield", Exacta, São Paulo, 7 (1), 121-131.

Bing, H., Chai, G.W., Staden, R.V., Guan, H. (2014). "Evaluation of doweled joints in concrete pavements using three-dimensional finite element analysis, design", Analysis, and Asphalt Material Characterization for Road and Airfield Pavements: 115-129.

Chandra, S., Viladkar, M.N., Nagrale, P.P. (2008). "Mechanistic approach for fiberreinforced flexible pavements", Journal of Transportation Engineering, 134 (1): 15-23.

Chun, S., Kim, K., Greene, J., Choubane, B. (2015). "Evaluation of interlayer bonding condition on structural response characteristics of asphalt pavement using finite element analysis and full-scale field tests", Construction and Building Materials, 96: 307-318.

Djellali, A., Houam, A., Saghafi, B., Hamdane, A., Benghazi, Z. (2017). "Static analysis of flexible pavements over expansive soils., International Journal of Civil Engineering, 15,:391-400.

Faheem, H., and Hassan, A.M. (2014). " $2 \mathrm{D}$ Plaxis finite element modeling of asphaltconcrete pavement reinforced with geogrid", Journal of Engineering Sciences Assiut University Faculty of Engineering, 42 (6): $1336-1348$.

Helwany, S., Dyer, J., Leidy, J. (1998). "Finite element analyses of flexible pavements", Journal of Transportation Engineering, 124 (5): 491-499.

Howard, I.L. and Kimberly, A.W. (2009). "Finite-element modeling of İnstrumented flexible pavements under stationary transient 
loading', Journal of Transportation Engineering, ASCE, 135(2): 53-61.

Imaninasab, R., Bakhshi, B., Shirini, B. (2016). "Rutting performance of rubberized porous asphalt using Finite Element Method (FEM)", Construction and Building Materials, 106: 382-391.

Kadela, M. (2016). " Model of multiple-layer pavement structure-subsoil system', Bulletin of The Polish Academy of Sciences Technical Sciences, 64 (4).

Khavassefat, P., Jelagin, D., Birgisson, B. (2015). "Dynamic response of flexible pavements at vehicle-road interaction', Road Materials and Pavement Design, 16 (2): 256276.

Kim, K., Tia, M. and Greene, J. (2016). Evaluation of structural behavior of precast prestressed concrete pavement with finite element analysis, Transportation Research Record: 84-93.

Lin, X., Zhang, Y.X., Hazell, P.J. (2014). "Modelling the response of reinforced concrete panels under blast loading", Materials and Design, 56: 620-628.

Ling, H.I. and Liu, Z. (2001). "Performance of geosynthetic-reinforced asphalt pavements", Journal of Geotechnical and Geoenvironmental Engineering, 127 (2): 177184.

Ling, H.I. and Liu, H. (2003). " Finite element studies of asphalt concrete pavement reinforced with geogrid', Journal of Engineering Mechanics, 129 (7): 801-811.

Liu, P., Wang, D., Oeser, M. (2017). "Application of semi-analytical finite element method to analyze asphalt pavement response under heavy traffic loads", Jouurnal of Traffic and Transportation Engineering, 4 (2): 206-214.

Mokhtari, A. and Nejad, F.M. (2012). '"Mechanistic approach for fiber and polymer modified SMA mixtures', Construction And Building Materials, 36:381-390.

Mulungye, R.M., Owende, P.M.O., Mellon, K. (2007). "Finite element modelling of flexible pavements on soft soil subgrades'. Materials and Design, 28: 739-756.

Ranadive, M.S. and Tapase, A.B. (2013). "Investigation of behavioral aspects offlexible pavement under various conditions by finite element method", Constitutive Modeling of Geomaterials, SpringerVerlag,Berlin: 765-770.

Rooholamini, H.,. Hassani, A., Aliha, M.R.M. (2018). "Evaluating the effect of macrosynthetic fibre on the mechanical properties of roller-compacted concrete pavement using response surface methodology', Construction and Building Materials, 159: 517-529.

Shafabakhsh, G.A., Family, A., and Abad, B.P.H. (2014). "Numerical analysis of concrete block pavements and comparison of its settlement with asphalt concrete pavements using finite element method', Engineering Journal, 18 (4): 39-51.

Tarefder, R.A., Ahmed, M.U., Islam, M.R., and Rahman, M.T. (2014). "Finite element model of pavement response under load considering cross-anisotropy in unbound layers'. Advances in Civil Engineering Materials, ASTM, 3 (1): 57-75.

Zhang, J., Zhu, C., Li, X., Pei, J., Chen, J. (2017). "Characterizing the three-stage rutting behavior of asphalt pavement with semi-rigid base by using UMAT in ABAQUS", Construction and Building Materials, 140: 496-507. 